\title{
TAXES AND ECONOMIC GROWTH IN ROMANIA. A VAR APPROACH
}

\author{
Mihai Ioan Mutaşcu ${ }^{1}$ \\ Dan Constantin Dănulețiu²
}

\begin{abstract}
The paper analyzes the relationship between taxes and economic growth in the case of Romania in the period January 1999 - March 2010, using an unrestricted Vector Autoregression Model (VAR) based on the rate of dynamic taxation's level and the rate of dynamic economic growth. The relationship is questioned in both directions, namely with reference to the manner in which taxes affect economic growth, but also in terms of the influence that economic growth exerts on taxes in the case of Romania for the mentioned period. The results show that tax policy in Romania cannot be taken to extremes, and should be very carefully implemented because a large amount of factors can influence the results
\end{abstract}

Keywords: tax, growth, VAR analysis, impulse functions, effects

JEL codes: E62, H21, O40

\section{Introduction}

The latest economic crisis has raised a series of questions about the measures that states have to take in order to stimulate economic activity. In this context, the idea that tax cuts will generate economic growth has re-emerged, every party involved in the debate bringing arguments based on the economic growth models that they favour.

In this paper we try to analyze the relationship between taxes and economic growth in the case of Romania in the period January 1999 - March 2010 with a view to clarifying the impact of the rate of dynamic taxation on economic growth, but also the impact of public decisions, in the context of economic growth, on the rate of taxation level. Based on the results obtained, we believe the decisions that Romanian public authorities make could be more realistic, including those made during the period under analysis.

In the case of Romania, other scholars such as Enache (2009) and Brasoveanu \& Brasoveanu (2008) performed multifactorial regression analyses using Barro and Sala-i-Martin's approach (2004). However, our investigation offers a particular type: we have chosen the VAR model because it allows us to study the impulse functions of the two variables we have considered: taxes and economic growth. The rest of the paper is organized as follows: section 2 surveys the relevant literature regarding the relationship between taxation and economic growth; section 3 presents the methodology of analysis and describes the variables and the results; section 4 is focused on conclusions.

\section{Literature review}

Economic theory has underlined the negative impact which taxes have on economic growth, as a result of the fact that taxation increases the cost of products or decreases consumer income. However, until the 1980s there was relatively little empirical research focused on the relationship

\footnotetext{
1 West University of Timişoara, Faculty of Economics and Business Administration, Romania, e-mail: mmutascu74@yahoo.com

2 “1 Decembrie 1918” University of Alba Iulia, Faculty of Science, Romania, e-mail: danuletiu.dan@gmail.com
} 
between taxation level and economic growth. In recent years, such studies have begun to emerge at the same time that the methods of analysis have become more diverse and accurate. Most of the studies testing empirically the relationship between taxation and economic growth have found a negative impact of the aggregate tax rate on economic growth, but there are some articles that do not find such results.

Some studies that aim to highlight the impact of taxation on economic growth have taken into account the average tax rate. In an article about models of growth, Ireland (1994) underlines that there are studies which suggest that average tax rates (tax revenue/GDP) are significantly and negatively related to growth in real income per capita (such as Cebula and Scott (1992), Marsden (1983), Skinner (1987), Martin and Fardmanesh (1990), Engen and Skinner (1992)), as well as studies that suggest that tax rates do not have important growth effects (such as Garrison and Lee (1992), Koester and Kormendi (1989), Easterly and Rebelo (1993)). Most of these studies are based on cross-section regression or time-series regression, except for that of Marsden (1983) which uses pair comparison for 20 countries. The majority of studies that take into account average tax rate have found that higher taxes are strongly correlated with reduced economic growth.

Using also cross-country regression analysis, Leibfritz et al. (1997) have suggested that an increase of $10 \%$ in the average tax ratio may have reduced OECD annual growth rates by about $0,5 \%$ in growth, and emphasized that direct taxation reduced growth marginally more than indirect taxation. In the same category, Mamatzakis (2005), using a dynamic impulse response analysis based on Greek data sets, has found that output growth responds negatively to an increase in the tax burden (measured by the ratio of total taxes over GDP). He also investigates the impact of growth on the tax burden and has found that this follows a cyclical pattern with a lag of one year. Koch et all. (2005), using tax and economic data specific to South Africa from the period 1960 to 2002 and a two-stage modelling technique to control for unobservable business cycle variables, examine the relationship between total taxation and economic growth and indicate that decreased tax burdens are strongly associated with increased economic growth potential. Another important finding is that developing economies are more influenced by tax changes than developed economies.

A quite different approach is that of Romer and Romer's (2007), which aims to research the effects generated by tax changes according to the reasons for which these changes have occurred. Consequently, the authors separate the tax changes between exogenous changes (related to economic growth or deficit decrease) and exogenous changes (contracyclical and spending-driven). Alternatively, they are measuring the tax changes through ,change in cyclically adjusted revenues”. The results obtained confirm that the changes effects on the economic growth differ according to these changes aim, the most relevant effect being that generated by an exogenous tax increase of one percent of GDP that lowers real GDP by roughly three percent. Moreover, one can state that taxes changes effects on the output are also related to other factors, not necessarily to the changes size, for instance, the perceived permanent character of changes, or the marginal taxes rates.

Karras and Furceri (2009), using a panel methodology that analyzes annual data from 1965 to 2003 for 26 OECD economies, find that higher taxes do indeed result in a reduction of GDP per capita that is sizable and persistent. While the exact size of the effect depends on how the "tax shock" is measured, the estimates of the authors suggest that an increase in the total tax rate by $1 \%$ of GDP will have a long-run effect on GDP per capita of $-0.5 \%$ to $-1.2 \%$. Stella Karagianni et all. (2009) have used the nonparametric Diks - Panchenko(2006) causality test to investigate the relationship between two alternative average tax rates, namely the ratio of total tax revenues to GDP and alternatively production tax rate, and economic growth for the United States. The current study emphasizes the fact that the production tax rate affects directly the economic growth rate and that the aggregate tax rate has no similar effects.

Trying to identify the optimal rate of taxation for Cote d'Ivoire, Keho (2010) has found that for the mentioned country a $1 \%$ increase in the tax burden would likely add $0.5 \%$ per year to economic growth, because the actual tax rates are substantially far beneath the optimal tax rate. 
However, Keho suggests that the impact of taxation on economic growth may also be influenced by the state's ability to collect taxes. If such ability is rather limited, then increasing taxes will only lead to tax evasion without ensuring any long term economic growth.

The second category of studies uses the marginal tax rate to suggest the influence of taxation on economic growth. One of the first studies in this category is that of Koester and Kormendi (1989). The authors believe that the tax revenue/GDP ratio is too general to be a good proxy for tax policy, so they consider that marginal tax rates have to be used as the proxy of tax policy. Following this idea, Koester and Kormendi have suggested a method for estimating average marginal tax rates, using a linear approximation and pointed out that the proposed method of estimating the marginal tax rate is robust only if there are no structural changes in the tax schedule over the sample period. In their paper, they have found that there is a negative but statistically insignificant coefficient of the marginal tax rate on growth.

An important contribution to the relevant literature is made by Padovano and Galli (2002) who, based on a panel of 25 industrialized countries from 1970 to 1998 , have shown that effective marginal tax rates and tax progressivity have a negative influence on economic growth. The study demonstrates that an increase of 10 percent in marginal tax rates leads to a decrease in the annual rate of economic growth by 0.23 percent.

Poulson and Kaplan (2008) explore the impact of tax policy on economic growth in American states within the framework of an endogenous growth model. Regression analysis is used to estimate the impact of taxes on economic growth in the states from 1964 to 2004 . The analysis reveals that higher marginal tax rates had a negative impact on economic growth and also shows that greater regressivity had a positive impact on economic growth.

Other studies suggest that there is a relationship between taxes as a source of revenue and economic growth. De Castro and de $\operatorname{Cos}(2006,2008)$ have estimated the effects of exogenous fiscal policy shocks in Spain in a VAR framework. They highlight the fact that the taxes increase are generating irrelevant positive effects over the GDP, as the effects on medium term are negative as a result of the budgetary expenditure raise. Based on these results, they consider that attempts to achieve fiscal consolidation by increasing the tax burden might end up in failure and are likely to involve even higher deficits in the future; also, in the medium term, this might slow down economic activity. Afonso and Sousa (2009) have used a new quarterly dataset covering 1979:1 - 2007:4, and resorted to a Bayesian Structural Autoregression model to analyze the macroeconomic effects of fiscal policy in Portugal. The empirical evidence suggests that government revenue shocks have a negative impact on GDP, on private consumption and on private investment, although the response emerges with a lag of about four quarters and leads to a fall in price level. In a more recent study, Afonso and Sousa (2011) find that a 1\% positive shock in government revenue is able to generate a positive response of GDP by $0.06 \%$, and an increase of both private consumption and private investment of $0.04 \%$ and $0.14 \%$, respectively. After this, the macroeconomic effects of the tax shock erode and even become negative. Kuismanen and Kämppi (2010) utilised the Vector Stochastic Process with Dummy Variables (VSPD) method to find out whether fiscal policy decisions have real effects on the economy of Finland. Their conclusion is that increases in public sector revenues seem to have a positive effect on investment and GDP. However, as they have noticed, it would be counterintuitive to claim that increased taxes would lead to increases in private sector activity and therefore it seems more plausible that a good economic era causes both the increases in public revenues and private sector activity.

The main studies about the effects of fiscal policy on economic growth in Romania (Enache, 2009; Brasoveanu and Brasoveanu, 2008) are based mostly on multifactorial regression. They use Barro and Sala-i-Martin's approach (2004) and do not underline the impact of the aggregate tax rate on economic growth but that of various other taxes. 


\section{Method and results}

We consider two variables in our investigation, the rate of dynamic taxation's level and the rate of dynamic economic growth. The data set covers the period January 1999 - March 2010 with reference to Romania, with quarterly frequency (42 observations).

a. The rate of dynamic taxation's level (DT) describes the real quarterly dynamic rate of taxation level in relative terms (\%). The taxation level represents the percentage of total taxes in GDP, and it has been taken from the Eurostat Online Database.

b. The rate of dynamic economic growth (DG) illustrates the real quarterly dynamic rate of GDP's level in relative terms (\%). GDP's level has been taken from the Eurostat Online Database.

Based on the working assumption/hypothesis $(H)$, we have performed an unrestricted Vector Autoregression Model (VAR) in order to investigate the relationship "DT- DG". As Cromwell et al. (1994) have indicated, such a model is commonly used for forecasting systems of interrelated time series and for analyzing the dynamic impact of random disturbances on the system of variables.

In vector autoregression models some variables are treated as endogenous and some as exogenous or predetermined (exogenous plus lagged endogenous). For our approach, the two variables - DT and DG - are treated as endogenous variables. Considering that each of VAR's equations contains $k$ lag values, for the $t$ period, we can write:

$$
\begin{aligned}
& D T_{t}=\alpha_{1}+\sum_{j=l}^{k} \beta_{j} D G_{t-j}+\sum_{j=l}^{k} \chi_{j} D T_{t-j}+u_{l t} \\
& D G_{t}=\alpha_{2}+\sum_{j=l}^{k} \varepsilon_{j} D G_{t-j}+\sum_{j=l}^{k} \varphi_{j} D T_{t-j}+u_{2 t}
\end{aligned}
$$

or, equivalently, in matrix form:

$$
\left[\begin{array}{c}
D T_{t} \\
D G_{t}
\end{array}\right]=\left[\begin{array}{l}
\alpha_{1} \\
\alpha_{2}
\end{array}\right]+\left[\begin{array}{l}
\beta_{1} \chi_{1} \\
\varepsilon_{1} \varphi_{1}
\end{array}\right]\left[\begin{array}{c}
D G_{t-1} \\
D T_{t-1}
\end{array}\right]+\ldots+\left[\begin{array}{l}
\beta_{k} \chi_{k} \\
\varepsilon_{k} \varphi_{k}
\end{array}\right]\left[\begin{array}{c}
D G_{t-k} \\
D T_{t-k}
\end{array}\right]+\left[\begin{array}{l}
u_{1 t} \\
u_{2 t}
\end{array}\right]
$$

where $\alpha_{1}, \alpha_{2}$ are the intercept terms; $\beta, \chi, \varepsilon, \phi$ are the coefficients of the endogen variables, and $u$ are the stochastic error terms.

The main steps we need to follow in order to perform the econometric analysis are: (a) unit root tests of variables; (b) joint lag selection and VAR; (c) stability test, and (d) residuals tests.

(a) Unit root tests of variables are based on Kwiatkowski-Phillips-Schmidt-Shin and NgPerron tests. The results, shown in Table 1 , suggest that DT is I(0), and DG is I(1). According to Vogelvang (2005), we have chosen the assumption/hypothesis "constant term", because an additional trend term is generally superfluous.

\begin{tabular}{|c|c|c|c|c|c|c|}
\hline \multirow{2}{*}{\multicolumn{3}{|c|}{ Explanation }} & \multicolumn{2}{|r|}{ KPSS } & \multicolumn{2}{|c|}{$\mathrm{Ng}$-Perron } \\
\hline & & & LM-Stat & LM-Stat & $\mathrm{MZa}$ & $\mathrm{MZa}$ \\
\hline \multicolumn{3}{|l|}{ Unit root } & Level & 1st diff. & Level & 1st diff. \\
\hline \multirow{4}{*}{ Variables } & \multirow{2}{*}{ Intercept } & DT & $0.102051 * * *$ & $0.171259 * * *$ & -3.53394 & 0.70973 \\
\hline & & $\overline{\mathrm{DG}}$ & $0.500000^{*}$ & $0.241360 * * *$ & -0.05429 & -0.00901 \\
\hline & \multirow{2}{*}{$\begin{array}{l}\text { Trend } \\
\text { and } \\
\text { intercept }\end{array}$} & DT & $0.047404 * * *$ & $0.074314 * * *$ & $-20.2689 *$ & $-41.0858 * * *$ \\
\hline & & DG & $0.184769 * *$ & $0.148854 * *$ & -0.16913 & -0.08336 \\
\hline
\end{tabular}

Table no. 1

KPSS and NP "unit root" tests of variables - level and $1{ }^{\text {st }}$ difference

Note: $* * *, * *$ and $*$ denotes significance at $\mathrm{p}<1 \%, 5 \%$ and $10 \%$. 
In our case, the difficulty in performing the VAR is that one of the series is stationary and the other is non-stationary. We worked on levels, as Harvey (1990) suggested, even if according to VAR methodologies all the variables should be stationary. Moreover, we did not choose the VEC approach because only one of the series is stationary (DT) and, as a consequence, these two series cannot be cointegated (for cointegation both series must have unit root). analysis.

(b) Joint lag selection and VAR illustrate the joint lag selection criteria and the VAR

For the selection of the joint lags we considered the VAR Lag Order Selection Criteria (Table no. 2). In the case of VAR "DT and DG", all the criteria (LR, FPF, AIC, SC and HQ) recommended a joint lag 4.

Table no. 2

VAR Lag Order Selection Criteria

\begin{tabular}{|c|c|c|c|c|c|c|}
\hline Lag & $\log L$ & LR & FPE & AIC & SC & HQ \\
\hline & $\begin{array}{ll}0 & 119.6561\end{array}$ & NA & $1.10 \mathrm{e}-05$ & -5.739320 & -5.655731 & -5.708882 \\
\hline & 1123.4017 & 6.943119 & $1.12 \mathrm{e}-05$ & -5.726912 & -5.476145 & -5.635596 \\
\hline & 2127.8873 & 7.877211 & $1.09 \mathrm{e}-05$ & -5.750601 & -5.332657 & -5.598409 \\
\hline & 3128.6913 & 1.333381 & $1.28 \mathrm{e}-05$ & -5.594696 & -5.009574 & -5.381627 \\
\hline & 4160.8550 & $50.20681^{*}$ & $3.27 \mathrm{e}-06^{*}$ & $-6.968537 *$ & $-6.216237^{*}$ & $-6.694591 *$ \\
\hline & 5162.4891 & 2.391416 & $3.72 \mathrm{e}-06$ & -6.853129 & -5.933651 & -6.518306 \\
\hline \multicolumn{7}{|c|}{$\begin{array}{l}\text { * indicates lag order selected by the criterion } \\
\text { LR: sequential modified LR test statistic (each test at } 5 \% \text { level) } \\
\text { FPE: Final prediction error } \\
\text { AIC: Akaike information criterion } \\
\text { SC: Schwarz information criterion } \\
\text { HQ: Hannan-Quinn information criterion }\end{array}$} \\
\hline
\end{tabular}

Moreover, the results in Table no. 3 show that we cannot reject the joint hypothesis that the coefficients of lags 1,2,3, and 5 are all equal to zero. Thus, we have used for our study the lag 4 .

Lag Exclusion Wald Test

\begin{tabular}{|llll|}
\hline \hline & DT & DGDP & Joint \\
\hline \hline Lag 1 & 13.73115 & 3.070409 & $\begin{array}{l}17.57211 \\
{[0.215412]}\end{array}$ \\
& {$[0.001043]$} & {$[0.01496]$} \\
Lag 2 & 12.10382 & 11.56302 & 25.50853 \\
& {$[0.002353]$} & {$[0.003084]$} & {$[3.97 \mathrm{e}-05]$} \\
Lag 3 & 4.014048 & 0.673991 & 4.925909 \\
& {$[0.134388]$} & {$[0.713912]$} & {$[0.294985]$} \\
Lag 4 & 7.360321 & 82.72201 & 92.20638 \\
& {$[0.025219]$} & {$[0.000000]$} & {$[0.000000]$}
\end{tabular}

Table no. 3 


\begin{tabular}{|llll|} 
Lag 5 & $\begin{array}{l}2.030786 \\
{[0.362260]}\end{array}$ & $\begin{array}{l}0.458128 \\
{[0.795278]}\end{array}$ & $\begin{array}{l}2.460712 \\
{[0.651684]}\end{array}$ \\
\hline \hline df & 2 & 2 & 4 \\
\hline \hline
\end{tabular}

Note: (a) Numbers in [ ] are p-values

(b) $* * *, * *$ and $*$ denotes significance at $\mathrm{p}<1 \%, 5 \%$ and $10 \%$.

In such conditions, for the joint lag 4, the "Unrestricted Vector Autoregression DT and DG" may be written (see the estimates in Table no. 4):

$$
\begin{aligned}
& D T_{t}=\alpha_{1}+\sum_{j=1}^{4} \beta_{j} D G_{t-j}+\sum_{j=1}^{4} \chi_{j} D T_{t-j}+u_{1 t} \\
& D G_{t}=\alpha_{2}+\sum_{j=1}^{4} \varepsilon_{j} D G_{t-j}+\sum_{j=1}^{4} \varphi_{j} D T_{t-j}+u_{2 t}
\end{aligned}
$$

Table no. 4

\begin{tabular}{|c|c|c|}
\hline Variables & DT & DG \\
\hline \multirow[t]{3}{*}{ DT(-1) } & -0.602435 & 0.199314 \\
\hline & $(0.17408)$ & $(0.13657)$ \\
\hline & {$[-3.46071]$} & [ 1.45943] \\
\hline \multirow[t]{3}{*}{ DT(-2) } & -0.601627 & 0.501071 \\
\hline & (0.19894) & $(0.15608)$ \\
\hline & {$[-3.02413]$} & [ 3.21043] \\
\hline \multirow[t]{3}{*}{ DT(-3) } & -0.274112 & 0.228578 \\
\hline & (0.19789) & $(0.15525)$ \\
\hline & {$[-1.38519]$} & [ 1.47234$]$ \\
\hline \multirow[t]{3}{*}{ DT(-4) } & -0.370522 & 0.196436 \\
\hline & $(0.16903)$ & $(0.13261)$ \\
\hline & {$[-2.19203]$} & [ 1.48131$]$ \\
\hline \multirow[t]{3}{*}{ DG(-1) } & -0.044301 & 0.008484 \\
\hline & $(0.06519)$ & $(0.05114)$ \\
\hline & {$[-0.67956]$} & [ 0.16588$]$ \\
\hline \multirow[t]{3}{*}{ DG(-2) } & -0.109628 & 0.138834 \\
\hline & $(0.06350)$ & $(0.04982)$ \\
\hline & {$[-1.72640]$} & [ 2.78679] \\
\hline \multirow[t]{3}{*}{ DG(-3) } & 0.000509 & 0.066978 \\
\hline & $(0.06277)$ & $(0.04924)$ \\
\hline & [ 0.00811$]$ & [ 1.36017] \\
\hline \multirow[t]{3}{*}{ DG(-4) } & -0.064753 & 0.485616 \\
\hline & $(0.06073)$ & $(0.04765)$ \\
\hline & {$[-1.06622]$} & [ 10.1923] \\
\hline \multirow[t]{3}{*}{$\mathrm{C}$} & 3.081384 & -0.818298 \\
\hline & $(0.61314)$ & $(0.48103)$ \\
\hline & [ 5.02557] & {$[-1.70115]$} \\
\hline
\end{tabular}

“Unrestricted Vector Autoregression DT and DG" estimates 


\begin{tabular}{|lrr|} 
& & \\
R-squared & 0.418883 & 0.803425 \\
Adj. R-squared & 0.278006 & 0.755771 \\
Sum sq. resids & 0.062128 & 0.038239 \\
S.E. equation & 0.043390 & 0.034041 \\
F-statistic & 2.973393 & 16.85939 \\
Log likelihood & 77.24535 & 87.43756 \\
Akaike AIC & -3.249779 & -3.735122 \\
Schwarz SC & -2.877421 & -3.362764 \\
Mean dependent & 1.002585 & 1.045643 \\
S.D. dependent & 0.051065 & 0.068881 \\
\hline \hline Determinant resid covariance (dof adj.) & & $2.16 \mathrm{E}-06$ \\
Determinant resid covariance & & $1.33 \mathrm{E}-06$ \\
Log likelihood & & 164.8749 \\
Akaike information criterion & -6.994042 \\
Schwarz criterion & -6.249326 \\
\hline \hline
\end{tabular}

Note: Standard errors in ( ) \& t-statistics in [ ]

(c) The VAR stability condition check test shows that the VAR satisfies the stability condition (Table no. 5).

VAR stability condition check test

Table no. 5

\begin{tabular}{|cc|}
\hline \hline Root & Modulus \\
\hline \hline 0.871297 & 0.871297 \\
-0.832985 & 0.832985 \\
$-0.578258-0.569853 \mathrm{i}$ & 0.811859 \\
$-0.578258+0.569853 \mathrm{i}$ & 0.811859 \\
$-0.018684-0.792744 \mathrm{i}$ & 0.792964 \\
$-0.018684+0.792744 \mathrm{i}$ & 0.792964 \\
$0.280810-0.690683 \mathrm{i}$ & 0.745586 \\
$0.280810+0.690683 \mathrm{i}$ & 0.745586 \\
\hline \hline \multicolumn{2}{|c|}{ No root lies outside the unit circle. } \\
VAR satisfies the stability condition. \\
\hline
\end{tabular}

(d) Residuals tests are focused on VAR Residual Portmanteau Tests for Autocorrelations, Residual Serial Correlation LM Tests, Unit Root Tests of VAR residuals, and the White Test for Residual Heteroskedasticity.

The results of the first two tests are illustrated in Tables no. 6 and no.7. 
VAR Residual Portmanteau Tests for Autocorrelations

Table no. 6

\begin{tabular}{|llllll|}
\hline \hline Lags & Q-Stat & Prob. & Adj Q-Stat & Prob. & df \\
\hline \hline & 2.528000 & NA* & 2.589658 & NA* & NA* \\
2 & 3.620287 & NA* & 3.736560 & NA* & NA* \\
3 & 6.471868 & NA* $^{*}$ & 6.807493 & NA* & NA* \\
4 & 8.874739 & NA* & 9.463298 & NA* & NA* \\
510.65200 & 0.0308 & 11.48073 & 0.0217 & 4 \\
\hline \hline
\end{tabular}

VAR Residual Serial Correlation LM Tests

Table no. 7

\begin{tabular}{|ccc|}
\hline \hline Lags & LM-Stat & Prob \\
\hline \hline 1 & 3.259823 & 0.5153 \\
2 & 1.932092 & 0.7482 \\
3 & 2.561574 & 0.6336 \\
4 & 4.220718 & 0.3770 \\
5 & 3.029610 & 0.5529 \\
\hline \hline
\end{tabular}

Both tests show that the null hypothesis of no serial autocorrelation in residuals cannot be rejected. The "unit root tests" of residuals suggest the same conclusions (Table 8). Cross-sections represent the number of residual series generated by VAR unrestricted equations (in our case 2 equations).

Table no. 8

The Unit Root Tests of VAR residuals

\begin{tabular}{|c|c|c|c|c|}
\hline Method & Statistic & Prob.** & $\begin{array}{l}\text { Cross- } \\
\text { sections }\end{array}$ & Obs \\
\hline \multicolumn{5}{|c|}{ Null: Unit root (assumes common unit root process) } \\
\hline Levin, Lin \& Chu t* & -6.84616 & 0.0000 & 2 & 82 \\
\hline Breitung t-stat & -6.29342 & 0.0000 & 2 & 80 \\
\hline \multicolumn{5}{|c|}{ Null: Unit root (assumes individual unit root process) } \\
\hline Im, Pesaran and Shin W-stat & -6.88272 & 0.0000 & 2 & 82 \\
\hline ADF - Fisher Chi-square & 43.9463 & 0.0000 & 2 & 82 \\
\hline PP - Fisher Chi-square & 43.7816 & 0.0000 & 2 & 82 \\
\hline \multicolumn{5}{|c|}{ Null: No unit root (assumes common unit root process) } \\
\hline Hadri Z-stat & -0.80487 & 0.7896 & 2 & 84 \\
\hline
\end{tabular}


Even if the heteroskedasticity is more relevant for the analysis of cross-section data than for time-series data (Vogelvang (2005)), the White Test has been used. The results are illustrated in Table no. 9, and they indicate that the variance of the disturbance term is constant (the null cannot be rejected).

VAR Residual Heteroskedasticity Tests with No Cross Terms

Table no. 9

\begin{tabular}{|lll|}
\hline \hline Chi-sq & df & Prob. \\
\hline \hline 48.71364 & 48 & 0.4441 \\
\hline \hline
\end{tabular}

The "Unrestricted Vector Autoregression DT and DG" model may be considered representative and stable in order to describe, for the case of Romania, the autoregressive connection between DT and DG and vice versa.

Based on the model proposed in this study, we can perform some impulse response functions. An impulse response function traces the effect of a one-time shock to one of the innovations on current and future values of the endogenous variables DT and DG - in this case, the accumulated responses of AGR and IGR to Generalized One S.D. Innovations \pm 2 S.E., for 10 years, are illustrated in the Graphics 1 and 2.

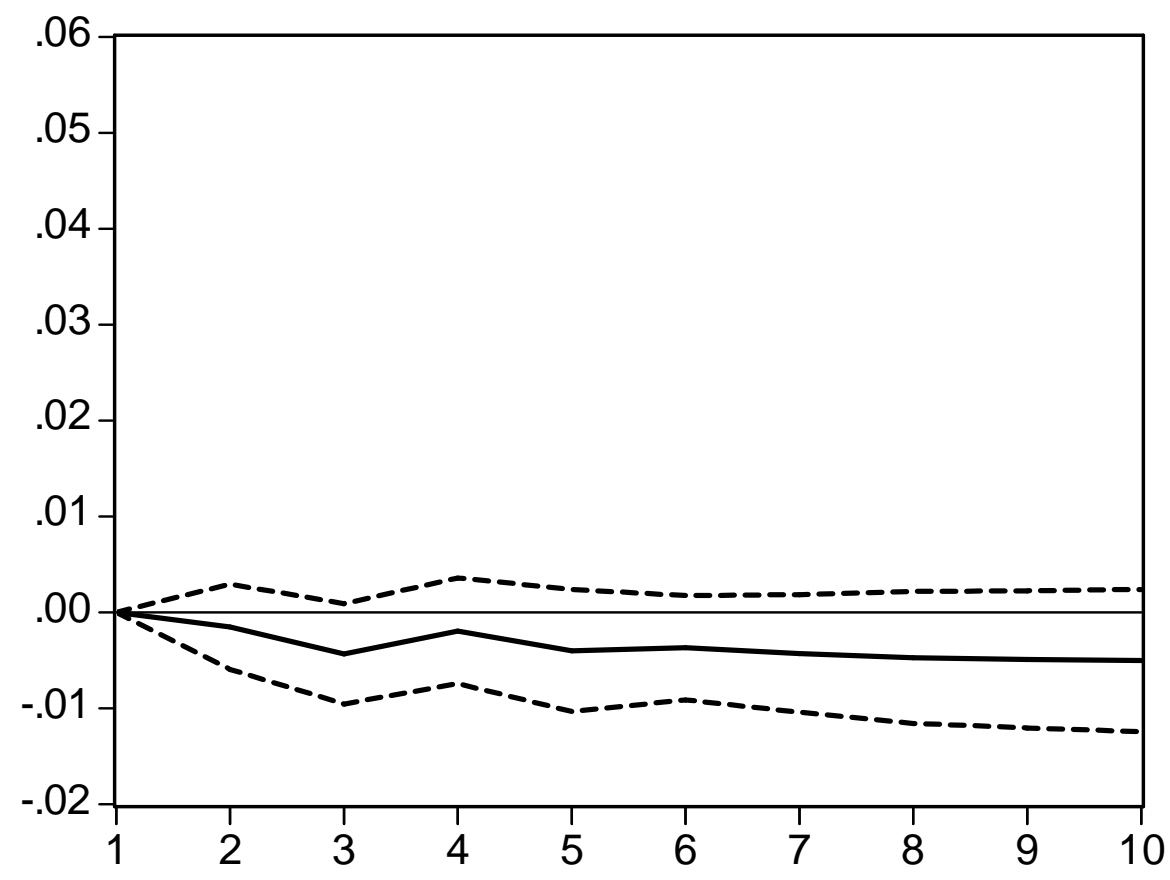

Graphic no. 1 - Accumulated Response of DT to DG 


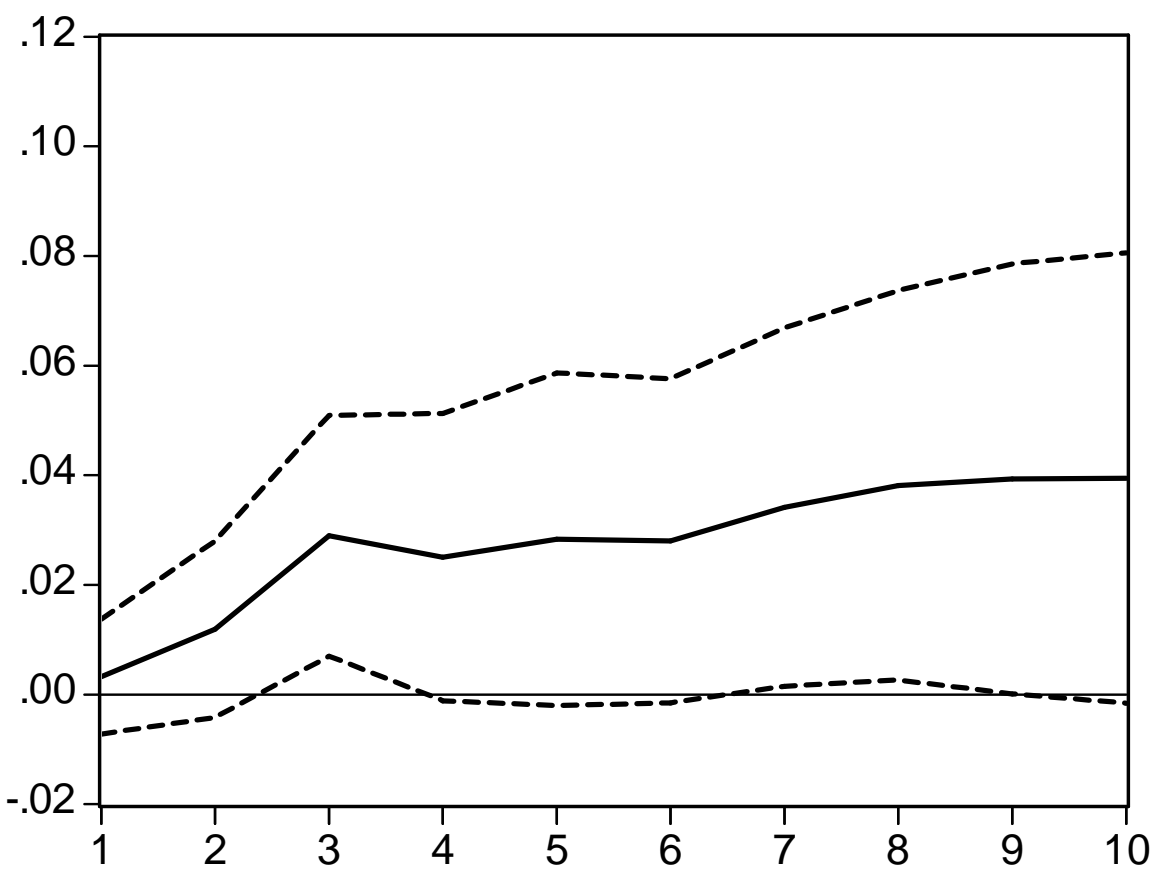

Graphic no. 2 - Accumulated Response of DG to DT

The results indicate that:

(1) A positive impulse in DG determines a flat decrease of DT's level in the medium and long term. There is a low intensity reaction in the first 2 years (short term), and a significant one during the rest of the interval; long term.

(2) A positive impulse in DT determines a significant increasing trend of DG's level in the

\section{Conclusions}

As the results show, an increase of DG determines a flat decrease of DT's level in the medium and long term. This effect is of low intensity in the first 2 years (short term), and increases significantly during the rest of the interval. As the GDP is the source of taxes, a rise in growth rates leads to a decrease in the level of tax constraints because the tax base increases (the tax rate is constant).

On the other hand, a positive shock in DT generates a rise in the level of economic growth in the long term. This reaction shows that, in the case of Romania, there are a lot of other factors that can stimulate economic growth, which have higher trend multiplier effects.

From a political point of view, in this context, the tax policy in Romania cannot be taken to extremes and should be very carefully implemented because a large amount of factors can influence the results. After 1989 in the new democratic Romanian socio-economic system, besides monetary policy, the tax policy has been strongly utilized in the field of economic policies. As the tax rate did not have a high level in the period under analysis, the rise of its amount did not seriously affect the level of GDP. Moreover, any change in the tax base has a strong elastic response in respect to the tax rate. On the other hand, an increase of the tax base determines a decrease of the tax rate. We have noticed that the decrease of tax rate does not necessarily involve a decrease of tax constraints on purchasing power. 


\section{References}

1. Afonso A., Sousa R.M., 2009. The Macroeconomic Effects of Fiscal Policy in Portugal: a Bayesian SVAR Analysis, Universidade do Minho, Working Paper series, online at http://www3.eeg.uminho.pt/economia/nipe/docs/2009/NIPE_WP_3_2009.pdf

2. Afonso A., Sousa R., 2011. The Macroeconomic Effects of Fiscal Policy in Portugal: a Bayesian SVAR Analysis, Portuguese Economic Journal, vol. 10(1), April

3. Barro R. J., Sala-i-Martin X., 2004. Economic Growth, 2nd ed., MIT Press, Cambridge, Massachusetts.

3. Braşoveanu L.O., Braşoveanu I., 2008. The Correlation between Fiscal Policy and Economic Growth, Theoretical and Applied Economics, volume 7, issue 7

4. Candelon B., Lieb L., 2011. Fiscal Policy in Good and Bad Times, METEOR, Maastricht Research School of Economics of Technology and Organization in its series Research Memoranda, online at http://edocs.ub.unimaas.nl/loader/file.asp?id=1569

5. Cromwell J.B., Labys W., Terraza M., 1994. Univariate Tests for Time Series Models, Quantitative Applications in the Social Sciences, Sage Publication.

6. de Castro Fernández F., Hernández de Cos P., 2006. The economic effects of exogenous fiscal shocks in Spain. A SVAR Approach, European Central Bank, Working paper series, online at http://www.ecb.europa.eu/pub/pdf/scpwps/ecbwp647.pdf

7. de Castro F., Hernandez de Cos P., 2008. The economic effects of fiscal policy: The case of Spain, Journal of Macroeconomics, Volume 30, Issue 3, September

8. Easterly W., Rebelo S., 1993. Fiscal Policy and Economic Growth: An Empirical Investigation, Journal of Monetary Economics, 32, December

9. Enache C., 2009. Fiscal policy and economic growth in Romania, Annales Universitatis Apulensis Series Oeconomica, 11(1)

10. Fu D., Taylor L.L., Yücel M.K., 2003. Fiscal policy and growth, Federal Reserve Bank of Dallas, Research Department Working Paper, online at http://www.dallasfed.org/research/papers/2003/wp0301.pdf

11. Harvey, A., 1990. The econometric Analysis of Time Series, The MIT Press, 2d ed., Cambridge, 83

12. Ireland P.N., 1994. Two perspectives on growth and taxes, Economic Quarterly, Federal Reserve Bank of Richmond, issue Win

13. Karagianni S., Pempetzoglou M., Saraidaris A., 2009. Average Tax Rates and Economic Growth: A Non-Linear Causality Investigation for the USA, 8th Annual European Economics and Finance Society (EEFS) Conference, Warsaw, Poland, 4-7 June, available online at: www.eefs.eu/conf/Warsaw/Papers/601a.doc

14. Karras G., Furceri D., 2009. Taxes and growth in Europe, South-Eastern Europe Journal of Economics, 2

15. Keho Y., 2010. Estimating the growth-maximizing tax rate for Cote d'Ivoire: Evidence and implications, Journal of Economics and International Finance, Vol. 2(9)

16. Koch S. F., Schoeman N. J., Van Tonder J. J., 2005. Economic growth and the structure of taxes in South Africa: 1960-2002. South African Journal of Economics, 73

17. Koester R. B., Kormendi R. C., 1989. Taxation, Aggregate Activity and Economic Growth: Cross-Country Evidence on Supply-Side Hypotheses, Economic Inquiry, 27

18. Kuismanen M. , Kämppi V., 2010. The effects of fiscal policy on economic activity in Finland, Economic Modelling, 27

19. Leibfritz, W., Thornton J., Bibbee A., 1997. Taxation and Economic Performance, OECD Economics Department Working Papers, No. 176, OECD Publishing.

20. Mamatzakis E. C., 2005. The dynamic responses of growth to tax structure for Greece, Applied Economics Letters, Volume 12, Issue 3 
21. Mutascu M., Fleischer A.M., 2011. Economic Growth and Globalization in Romania, World Applied Sciences Journal 12 (10)

22. Padovano F., Galli E., 2002. Comparing the Growth Effects of Marginal vs. Average Tax Rates and Progressivity, European Journal of Political Economy, 18

23. Poulson B. W., Kaplan J.G., 2008. State Income Taxes and Economic Growth, Cato Journal 28(1)

24. Romer C.D., Romer D.H., 2007. The Macroeconomic Effects of Tax Changes: Estimates Based on a New Measure of Fiscal Shocks, NBER Working Paper No. 13264, online at http://www.nber.org/papers/w13264

25. Romer C.D., Romer D.H., 2010. The Macroeconomic Effects of Tax Changes: Estimates Based on a New Measure of Fiscal Shocks, American Economic Review, American Economic Association, vol. 100(3), June

26. Vogelvang, B., 2005. Econometrics. Theory and Applications with EViews, Pearson Education Limited. 